\title{
Anti-Intrusion Effect of Lorazepam: An Experimental Study
}

\author{
Hong-Seock Lee ${ }^{1}$, Heung-Pyo Lee ${ }^{2}$, Sang-Kyu Lee ${ }^{3}$, Yong-Ku Kim ${ }^{4}$ and Yun-Kyeung Choi ${ }^{\varpi}$ \\ 1Department of Psychiatry, Kangnam Sacred Heart Hospital, Hallym University Medical Center, Seoul, Republic of Korea \\ ${ }^{2}$ Department of Psychology, Daegu Cyber University, Daegu, Republic of Korea \\ ${ }^{3}$ Department of Psychiatry, Chuncheon Sacred Heart Hospital, Hallym University Medical Center, Chuncheon, Republic of Korea \\ ${ }^{4}$ Department of Psychiatry, Korea University Medical Center, Korea University Ansan Hospital, Ansan, Republic of Korea \\ ${ }^{5}$ Department of Psychology, Keimyung University, Daegu, Republic of Korea
}

Objective Easy triggering of trauma-related episodic memory fragments caused by perceptual cues is tied to strong perceptual priming in the implicit memory system. And among benzodiazepines, only lorazepam has been consistently reported to have an atypical suppression effect on perceptual priming processes. The aim of this study was to investigate the effects of single doses of lorazepam, diazepam, and a placebo on intrusive memories after exposure to a distressing videotape and to explore whether the anti-intrusive effect of lorazepam is acquired as a result of the suppression of perceptual but not conceptual priming processes.

Methods Under prospective, randomized, and double-blind conditions, we compared the anti-intrusion effect of a single dose of lorazepam $(n=22)$ with that of diazepam $(n=22)$ and a placebo $(n=21)$ in young healthy Korean college students following exposure to a traumatic videotape.

Results We present the first finding for an anti-intrusion effect of lorazepam. One day after the medication, lorazepam, rather than diazepam or the placebo, significantly reduced the extent of intrusion and data-driven processing of the traumatic information. There were no differences among the three conditions in state anxiety, depression, and an arousal scale throughout the experiment.

Conclusion Results from this study suggest the possibility of lorazepam as a candidate anti-intrusion drug, as well as the cautious use of diazepam in the treatment of PTSD patients. The anti-intrusive effect of lorazepam is directly related to its atypical inhibitory effect on implicit perceptual priming processes. The present study provides support for the enhanced perceptual priming hypothesis of PTSD.

Psychiatry Investig 2013;10:273-280

Key Words Trauma, Memory, Perception, Lorazepam, Diazepam.

\section{INTRODUCTION}

A core feature of posttraumatic stress disorder (PTSD) is the unwanted re-experiencing of intrusive memories. Intrusive trauma memories are rich multi-modal mental images of highly detailed sensory impressions of the traumatic events including sights, sounds, feelings, and bodily sensations. ${ }^{1}$ Intrusive memories appear involuntary, thereby implying that the underlying mechanisms governing their retrieval are automatic. $^{2}$ Intrusive memories may vary from mildly distressing images to full-blown flashbacks, where the trauma survivor is

Received: May 26, 2013 Revised: July 2, 2013

Accepted: July 2, 2013 Available online: September 16, 2013

$\triangle$ Correspondence: Yun-Kyeung Choi, $\mathrm{PhD}$

Department of Psychology, Keimyung University, 1095 Dalgubeol-daero, Dalseogu, Daegu 704-701, Republic of Korea

Tel: +82-53-580-5405, Fax: +82-53-580-5313, E-mail: ykchoi@kmu.ac.kr

(a) This is an Open Access article distributed under the terms of the Creative Commons Attribution Non-Commercial License (http://creativecommons.org/licenses/by$\mathrm{nc} / 3.0$ ) which permits unrestricted non-commercial use, distribution, and reproduction in any medium, provided the original work is properly cited. completely absorbed in the memory and temporarily loses touch with the here-and-now. ${ }^{1}$

Clinical and theoretical models of PTSD have assumed that intrusive memories are associated with the way the traumatic events are encoded, organized in memory, and retrieved. ${ }^{3-5}$ For example, the relative balance of data-driven versus conceptual processing ${ }^{6}$ during encoding is a major factor determining whether the traumatic event subsequently becomes intrusive. If the individual lacks conceptual processing (i.e., processing the meaning of the situation, processing it in an organized way and placing it into context) and engages mainly in data-driven processing (i.e., processing the sensory impressions) during a traumatic event, then the traumatic memory will be relatively difficult to retrieve intentionally. At the same time, there will be relatively strong perceptual priming for the accompanying stimuli. ${ }^{5}$ Intrusive trauma memories can be highly distressing and impairing. Therefore, the main interest of treatment for PTSD has been to reduce intrusive memories.

In reviewing psychopharmacological studies on memory in 
order to determine the candidate anti-intrusion drug, we paid special attention to the atypical effect of lorazepam on memory systems compared to other benzodiazepines (BZs). All BZs induce a similar transient amnesic effect on the explicit memory system, characterized by impaired episodic memory, 7,8 but spared semantic memory. ${ }^{9}$ However, there is substantial evidence identifying lorazepam as qualitatively different in its effects on cognitive processes relative to other BZs (e.g., diazepam). ${ }^{10}$ Only lorazepam has been found to consistently impair performance on perceptual priming tasks ${ }^{11-16}$ without impairing conceptual priming. ${ }^{17}$ These findings suggest the possibility that lorazepam may impair some aspects of automatic processes.

As a suitable comparison drug to lorazepam, diazepam preserves episodic memory ${ }^{18-22}$ and perceptual priming, ${ }^{23,24}$ but conceptual priming becomes impaired. ${ }^{16}$ Therefore, diazepam should increase the extent of intrusions of traumatic memories.

While almost all studies investigated the effects of BZs on memory when it is given prior to information acquisition, few report the effects of lorazepam on information storage and retrieval. Previous studies have only showed that lorazepam might impair the acquisition of information (i.e., the encoding process). However, impaired performance is not evident when lorazepam is administered immediately after the acquisition of information (i.e., storage and retrieval).$^{10}$ In clinical settings, trauma survivors experience intrusive memories, and then take medications to control their symptoms. Therefore, the experiment procedure should be modified to examine the effects of lorazepam on information storage and retrieval, and the drug should be administered after traumatic stimuli are shown.

Intrusive memories can be elicited in a laboratory environment using the 'trauma film paradigm. ${ }^{25}$ Intrusive memories in the laboratory are similar to those formed in the natural environment. Importantly, in the laboratory, it is possible to control the factors associated with the intrusiveness of traumatic memories, such as type, severity, and duration of the traumatic experience.

In the present study, we simulated a clinical trial of lorazepam for PTSD by exposing young healthy college students to distressing traumatic videotape.

The aim was to investigate the effects of single doses of lorazepam, diazepam, and a placebo on intrusive memories after exposure to a distressing videotape. To achieve this goal, we assumed that treatments that inhibit involuntary episodic retrieval and perceptual priming would reduce the extent of the intrusions, and that lorazepam would impair theses automatic memory processes. By contrast, we expected that any treatment that saves or enhances episodic memory and perceptual priming tasks but impairs semantic memory and conceptual priming would induce intrusion. Therefore, we hypothesized that only lorazepam out of the three would reduce the intrusive thoughts. In addition, to explore whether the anti-intrusive effect of lorazepam is acquired as a result of the suppression of perceptual but not conceptual priming process, the extent of data-driven versus conceptual processing of traumatic memories was also examined.

\section{METHODS}

\section{Subjects}

Seventy-five participants enrolled at Chungnam National University as students were recruited via an advertisement in a local newspaper. None of them had participated in similar studies. All of them completed a questionnaire asking about their use of drugs, tobacco, and alcohol in order to ensure that the subjects were free from any memory affecting substances at least one week before the trial. Six students were excluded: 3 for alcohol use and 3 for the use of anti-cholinergic drugs. Two students were excluded because they met criteria for partial PTSD in the Structured Clinical Interview for DSMIV Axis I disorders (SCID) ${ }^{26}$ An additional two subjects were eliminated because their avoidance (e.g., closing eyes, turning their head around) during the trauma video film exposure phase was severe enough to disrupt the experiment. The video consisted of 15 minutes of terrifying real-life footage compiled by one of the researchers (SK-L) displaying dead bodies, physical injuries, car accidents, mob violence, executions, atrocities of POW, and natural disasters. Prior to the experiment, informed consent was obtained from all participants, which stated that the experimental video contained graphic material which could be disturbing, and that they were free to withdraw at any time without penalty.

A total of 65 Korean college students composed the final sample. The mean age of the participants was 22.5 years $(\mathrm{SD}=$ 1.8). The participants consisted of 35 women (age $\mathrm{M}=22.0$ years, $\mathrm{SD}=1.7$ ) and 30 men (age $\mathrm{M}=23.0$ years, $\mathrm{SD}=1.8$ ).

\section{Study design}

This experiment was conducted in a randomized, doubleblind and placebo-controlled trial, comparing the anti-intrusion effect of two BZs and a placebo by using a PTSD-simulation method over one week and at a fixed single dose. The study was approved by the School of Medicine of the Hallym University Ethics Committee.

\section{Procedure}

Figure 1 presents an overview of the study procedure. Participants visited our laboratory four times. In the pre-experi- 


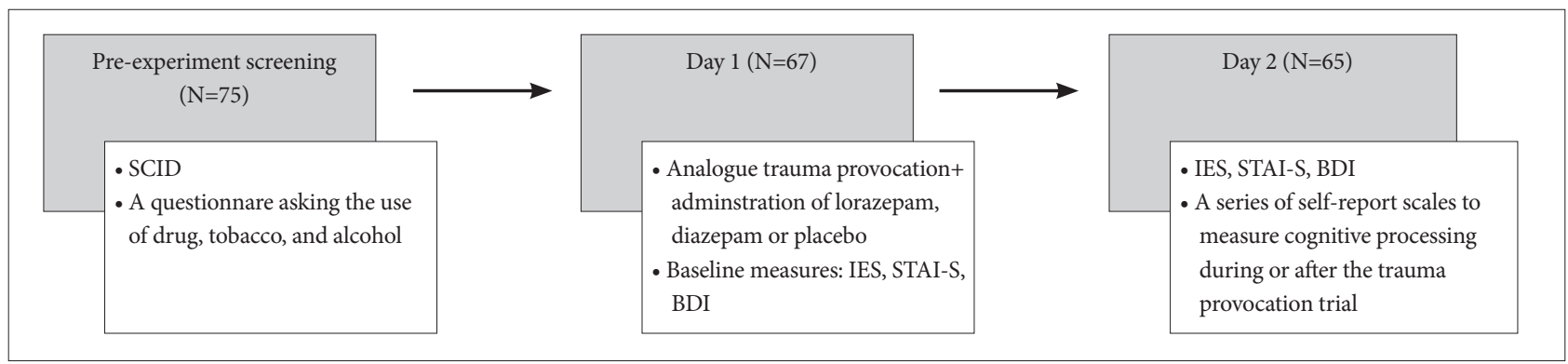

Figure 1. Overview of the study procedure. SCID: Structured Clinical Interview for DSM-IV Axis I disorders, IES: Impact of Event Scale, STAI-S: State and Trait Anxiety Inventory-State, BDI: Beck depression inventory.

ment screening phase, the SCID and a questionnaire asking the use of drug, tobacco, and alcohol were administered. After an initial session, each subject made three visits to the lab.

On Day 1 of the experiment, a total of 67 participants watched a 15 minute movies of terrifying real-life footage on a 56 inch screen while seated 10 feet away. Subjects were asked to keep their eyes on the screen and non-compliance with this instruction (e.g., closing eyes, turning their head around) was monitored by a research assistant. They were randomly assigned by computer-generated numbers to treatments of a single dose of an oral capsule either with lorazepam $(0.5 \mathrm{mg})$, diazepam ( $5 \mathrm{mg}$ : a dose equivalent to $0.5 \mathrm{mg}$ of lorazepam) or a placebo $(0.5 \mathrm{mg})$, approximately 120 minutes after the trauma provocation trial. In order to satisfy the requirement of a double-blind study, all capsules appeared the same. In addition, a researcher who was blind to the study asked the subjects to swallow the capsules in one gulp without inspecting, smelling, tasting, or chewing it. The experimenters (HS-L, SJ$\mathrm{K}, \mathrm{SH}-\mathrm{S}, \mathrm{SH}-\mathrm{L}$ and EJ-L) could not predict what treatment condition each subject was assigned to because the allocation list was kept locked by a non-acting researcher (SK-L) in an undisclosed university office in a different city as the testing site, and its exact location was not revealed throughout the monitoring sessions. Participants were told that they should not drive a car for at least for 4 hours. Participants did not report any significant adverse effects or complaints after taking the medication.

Approximately 60 minutes after the experiment, the subjects were asked to complete the baseline measures for depression and state anxiety using the Korean version of the Beck depression inventory $(\mathrm{BDI})^{27}$ and the state and trait anxiety inventory (STAI) ${ }^{28}$ in order to control their confounding effects on PTSD-related symptoms. During this baseline period, PTSD-related symptoms were measured using the Korean version of the Impact of Event Scale (IES). ${ }^{29,30}$

During the follow-up phase, subjects completed the daily Posttraumatic stress Diagnostic Scale (PDS) ${ }^{31}$ and were asked to visit the laboratory again to complete measures including the IES, BDI, and STAI-S on Day 2 and Day 7 of the experiment.
On Day 2, all of the participants completed a series of self-report scales to measure cognitive processing during or after the trauma provocation trial.

\section{Study tools}

Primary outcome measures: Posttraumatic Diagnostic Scale (PDS) and Cognitive Processing Measures

Posttraumatic Diagnostic Scale (PDS)

Daily frequency of analogue PTSD symptoms was assessed using the daily PTSD symptoms questionnaire, of which items of the original PDS ${ }^{31}$ asking the frequency of the three PTSD core symptoms within the past week were changed into the items asking the daily frequency. The response format was a 4-point Likert scale, ranging from 0 ("never") to 3 ("5 times or more per day or almost always") and was used to calculate PT$\mathrm{SD}$ symptom severity scores for each of the symptom clusters.

\section{Cognitive Processing Measures}

Self-report measures of cognitive processing during trauma were developed in a series of studies. ${ }^{32,33}$ Conceptual processing was measured with the conceptual processing subscale from the Cognitive Processing Questionnaire (CPQ). The CPQ was developed to assess perceptual versus conceptual processing of traumatic materials. ${ }^{34}$ The conceptual processing scale consists of 7 items measuring deeper processing of the meaning of the situation (e.g." "I had a clear impression of how one event followed from another").

Data-driven processing was measured with the Data-Driven Processing Scale. ${ }^{35}$ This scale consists of 8 items measuring the extent to which participants primarily engaged on a superficial level while watching the trauma film. The Data-Driven Processing Scale has previously been shown to have internal consistencies in patient and student populations (Cronbach's alphas of 0.7 and above $)^{35}$ and can predict the development of analogue PTSD symptoms and disorganized narratives following exposure to a distressing videotape, ${ }^{34}$ assault ${ }^{32}$ and motor vehicle accident. ${ }^{32}$ 
Dissociation during watching the trauma film was measured with the State Dissociation Questionnaire (SDQ). ${ }^{33}$ This is a 9 item scale measures peritraumatic dissociative experiences, such as derealization, depersonalization, detachment, altered time sense, and emotional numbing. The SDQ has good reliability and validity ${ }^{33,34}$ and correlates highly with the Peritraumatic Dissociation Scale.

Self-referent processing was measured with the Lack of SelfReferent Processing Scale. This scale is a self-report measure which assesses the extent to which participants processed the assault as happening to themselves and incorporated the experience with other autobiographical information relating to the self (e.g., "I felt as if it was happening to someone else", "I felt cut off from my past", Cronbach's alpha=0.88). A higher score on this questionnaire indicates less self-referent processing. The scale has been demonstrated to predict the development of PTSD symptoms in survivors of motor vehicle accidents. $^{32}$

\section{Secondary outcome measures: state-anxiety and depression}

Participants also completed the Korean version of the BDI, which was validated by Lee and Song ${ }^{36}($ alpha $=0.85)$ and the Korean version of the STAI-S, which was standardized by Kim and $\operatorname{Shin}^{37}$ (alpha=0.86).

\section{Statistical analyses}

Values of interest for each experimental day were summarized by computing the means and SD of the three medication groups. Parametric data at baseline were analyzed by a oneway ANOVA, followed by the Duncan test when appropriate. The non-parametric data, expressed as percentages, were an- alyzed by a $\chi^{2}$ test. An analysis of covariance (ANCOVA), using the baseline (Day 1) score as a covariate, was used to determine when significant lorazepam-diazepam-placebo differences took place on the IES, STAI-S and BDI. For subsequent group comparisons, we used Bonferroni adjustments for multiple comparisons. Correlations were calculated between measures of intrusion and cognitive processing styles. Differences were considered to be statistically significant when $\mathrm{p}<0.05$.

\section{RESULTS}

\section{Demographic data}

The three groups did not differ with respect to sex $\left(\chi^{2}=0.227\right.$, $\mathrm{df}=2, \mathrm{p}=0.893]$, age $[\mathrm{F}(2,62)=0.201, \mathrm{p}=0.818]$, and economic status $\left(\chi^{2}=9.051, \mathrm{df}=6, \mathrm{p}=0.171\right)$. Baseline symptom scores on the STAI-S, BDI, and IES, which were measured after the analogue trauma provocation trial, did not show any significant differences among the three treatment groups $[\mathrm{F}(2,62)=1.939$, $\mathrm{p}=0.153 ; \mathrm{F}(2,62)=0.359, \mathrm{p}=0.700 ; \mathrm{F}(2,62)=0.230, \mathrm{p}=0.795$, respectively]. The groups did not differ in terms of how depressive and anxious they felt after watching the film.

\section{Primary outcome}

The PTSD-related results revealed by the ANCOVA with measures of Day 1 as covariates are shown in Table 1 . The ANCOVA revealed that the three treatment groups did not differ in arousal $[\mathrm{F}(2,61)=0.728, \mathrm{p}=0.487]$, but did in intrusion score on the $\operatorname{IES}[F(2,61)=3.960, p=0.024]$. Subsequent analysis showed that the mean score of intrusion in the lorazepam group decreased relative to that in the diazepam group $(\mathrm{p}=$ 0.022 ). These results suggest that a single dose of lorazepam may speed up recovery from intrusive memories. Diazepam

Table 1. PTSD-related symptom of three groups at day 1 and day 2

\begin{tabular}{|c|c|c|c|c|c|c|c|c|}
\hline \multirow{2}{*}{ IES } & \multicolumn{2}{|c|}{ Lorazepam $(\mathrm{N}=22)$} & \multicolumn{2}{|c|}{ Diazepam $(\mathrm{N}=22)$} & \multicolumn{2}{|c|}{ Placebo $(\mathrm{N}=21)$} & \multirow{2}{*}{ p-value* } & \multirow{2}{*}{ partial $\eta^{2}$} \\
\hline & Day 1 & Day 2 & Day 1 & Day 2 & Day 1 & Day 2 & & \\
\hline Intrusion & $5.1 \pm 4.4$ & $2.9 \pm 2.6$ & $5.9 \pm 3.4$ & $6.2 \pm 4.6$ & $5.0 \pm 4.1$ & $4.8 \pm 3.8$ & 0.024 & 0.115 \\
\hline Arousal & $5.6 \pm 4.2$ & $5.5 \pm 5.2$ & $6.0 \pm 3.3$ & $7.2 \pm 4.3$ & $5.5 \pm 4.5$ & $5.9 \pm 4.3$ & 0.487 & 0.023 \\
\hline Total score & $10.8 \pm 7.5$ & $8.5 \pm 7.4$ & $11.9 \pm 6.3$ & $13.4 \pm 8.6$ & $10.5 \pm 7.7$ & $10.7 \pm 7.4$ & 0.140 & 0.062 \\
\hline
\end{tabular}

All values are means \pm SD. *based on ANCOVA with scores of day 1 as covariates. IES: impact of event scale, PTSD: post-traumatic stress disorder, ANCOVA: analysis of covariance

Table 2. Cognitive processing styles between three-treatment groups at day 2

\begin{tabular}{|c|c|c|c|c|c|}
\hline & Lorazepam (N=22) & Diazepam $(\mathrm{N}=22)$ & Placebo $(\mathrm{N}=21)$ & p value* & Cohen's $\mathrm{d}^{\dagger}$ \\
\hline Conceptual processing & $19.41 \pm 3.43$ & $19.09 \pm 2.31$ & $20.43 \pm 2.91$ & 0.301 & 0.11 \\
\hline Data-driven processing & $15.31 \pm 4.53$ & $19.32 \pm 5.43$ & $19.90 \pm 5.17$ & 0.007 & 0.80 \\
\hline State dissociation & $16.09 \pm 5.64$ & $19.50 \pm 7.51$ & $18.14 \pm 5.92$ & 0.215 & 0.51 \\
\hline Self-referent processing & $16.05 \pm 6.54$ & $17.95 \pm 6.59$ & $16.71 \pm 5.52$ & 0.592 & 0.29 \\
\hline
\end{tabular}

All values are means \pm SD. *based on ANCOVA with scores of day 1 as covariates, ${ }^{\dagger}$ effect size: Lorazepam vs. Diazepam. ANCOVA: analysis of covariance 
had the opposite effect on some measures.

The results of an one-way ANOVA for the effect of treatments on cognitive processing of traumatic information are shown in Table 2 . The results revealed that there were no significant differences in conceptual processing $[\mathrm{F}(2,62)=1.224$, $\mathrm{p}=0.301]$, state dissociation $[\mathrm{F}(2,62)=1.574, \mathrm{p}=0.215]$, and self-referent processing $[\mathrm{F}(2,62)=0.528, \mathrm{p}=0.592]$. Only datadriven processing between treatment groups was significant $[\mathrm{F}(2,62)=5.337, \mathrm{p}=0.007]$, and the Duncan test indicated that diazepam and placebo groups reported more data-driven processing than the lorazepam group (Figure 2).

\section{Secondary outcome}

The secondary results of ANCOVA with measures of Day 1 as covariates are shown in Table 3. The ANCOVA revealed

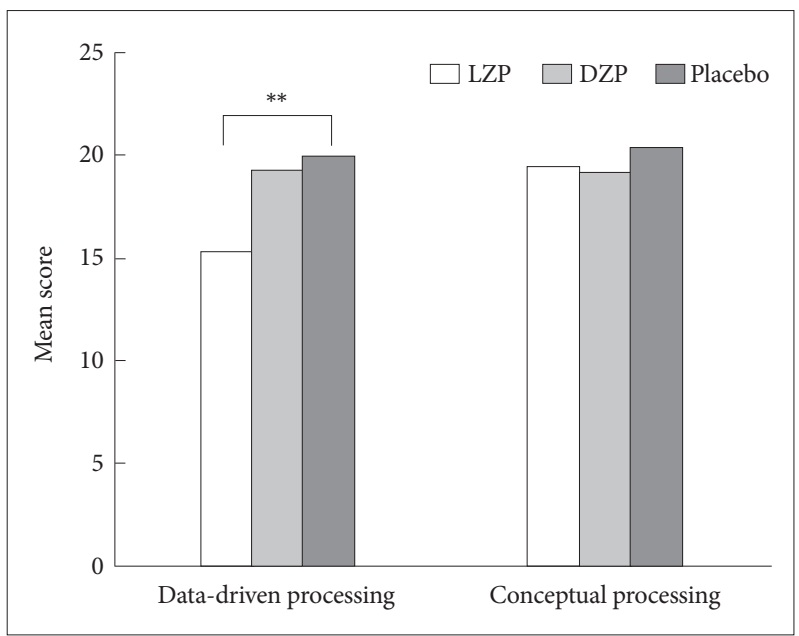

Figure 2. Effects of treatments on cognitive processing of trauma-related materials at day 2. ${ }^{* *} p=0.007$ : Lorazepam (LZP) vs. Placebo and Diazepam (DZP). that the three treatment groups did not differ in state anxiety $[F(2,61)=0.684, p=0.509]$ and depression $[F(2,61)=0.251, p=$ $0.779]$.

\section{Relationships between cognitive processing and intrusions}

Table 4 shows the correlation coefficients ( $r$ values) between cognitive processing and intrusions. The results showed that there were strong correlations between intrusion at Day 2 and data-driven processing $[\mathrm{r}(65)=0.55, \mathrm{p}<0.001]$, state dissociation $[\mathrm{r}(65)=0.44, \mathrm{p}<0.001]$, and self-referent processing $[\mathrm{r}(65)=0.51, \mathrm{p}<0.001]$. As expected, we observed no significant relationships between intrusions and conceptual processing.

\section{DISCUSSION}

This experimental study is the first that has examined the effect of lorazepam and diazepam on the intrusiveness of traumatic materials. Results from the current study suggest the possibility of lorazepam as a candidate anti-intrusion drug and the cautious use of diazepam in the treatment of PTSD patients. In this study, approximately 24 hours after the medication, the difference between the groups remained only in the dimension of intrusion: the intrusion was significantly decreased by lorazepam compared with diazepam and placebo, while the difference disappeared in the dimension of arousal. Note that only lorazepam was associated with less data-driven processing than diazepam and placebo. Taken together, these results suggest that the decrease of intrusion in the placebo and diazepam groups resulted from the influence of time (i.e., amnestic effect), while lorazepam produced an anti-in-

Table 3. State anxiety and depression of three-treatment groups at day 1 and day 2

\begin{tabular}{|c|c|c|c|c|c|c|c|c|}
\hline & \multicolumn{2}{|c|}{ Lorazepam $(\mathrm{N}=22)$} & \multicolumn{2}{|c|}{ Diazepam $(\mathrm{N}=22)$} & \multicolumn{2}{|c|}{ Placebo $(\mathrm{N}=21)$} & \multirow{2}{*}{ p value* } & \multirow{2}{*}{ partial $\eta$} \\
\hline & Day 1 & Day 2 & Day 1 & Day 2 & Day 1 & Day 2 & & \\
\hline $\mathrm{SA}^{\dagger}$ & $37.1 \pm 6.3$ & $44.9 \pm 10.1$ & $41.4 \pm 8.4$ & $49.4 \pm 11.6$ & $40.2 \pm 7.7$ & $50.1 \pm 10.0$ & 0.509 & 0.022 \\
\hline $\mathrm{D}^{\ddagger}$ & $7.2 \pm 4.2$ & $6.6 \pm 5.9$ & $6.8 \pm 3.6$ & $6.9 \pm 4.3$ & $8.0 \pm 6.4$ & $7.8 \pm 6.4$ & 0.779 & 0.008 \\
\hline
\end{tabular}

All values are means \pm SDs. *based on ANCOVA with measures of day 1 as covariates, ${ }^{\dagger}$ measured by State and Trait Anxiety Inventory, ${ }^{\ddagger}$ measured by Beck’s Depression Inventory. SA: state anxiety, D: depression, ANCOVA: analysis of covariance

Table 4. Correlation coefficients between cognitive processing and intrusion at day 1 and day 2

\begin{tabular}{|c|c|c|c|c|c|}
\hline & 1 & 2 & 3 & 4 & 5 \\
\hline 1. Intrusion at day 1 & 1 & & & & \\
\hline 2. Intrusion at day 2 & 0.21 & 1 & & & \\
\hline 3. Conceptual processing & 0.03 & 0.01 & 1 & & \\
\hline 4. Data-driven processing & $0.26^{*}$ & $0.55^{* * *}$ & 0.05 & 1 & \\
\hline 5. State dissociation & $0.30^{*}$ & $0.44^{* * *}$ & -0.03 & $0.70^{* * *}$ & 1 \\
\hline 6. Self-referent processing & $0.30^{*}$ & $0.50^{* * *}$ & 0.01 & $0.56^{* * *}$ & $0.74^{* * *}$ \\
\hline
\end{tabular}

${ }^{*} \mathrm{p}<0.05,{ }^{* * *} \mathrm{p}<0.001$ 
trusion effect by its own pharmacodynamic properties and influenced cognitive processing. In addition, it was reported that lorazepam produce impairment of an Ach-dependent central pathway, ${ }^{38}$ which has a central role in memory function, whereas diazepam has less pronounced effects, in particular on implicit memory. ${ }^{15,22}$ These findings of the previous works might provide an explanation of why lorazepam and diazepam show different effect on intrusion of traumatic memory. Given that intrusion plays a role in the development of hyperarousal and avoidance, however, continuous medication of lorazepam may have positive effects on other PTSD symptom clusters. Further studies on this possibility are needed.

Ehlers and Clark ${ }^{5}$ suggested that the easy triggering of intrusive memories in PTSD by perceptually similar cues is a function of strong perceptual priming to stimuli that occurred shortly before or during the traumatic event. This enhanced perceptual priming hypothesis of PTSD for intrusive memories receives consistent empirical and experimental support. ${ }^{39,40}$ Our finding provides support for the enhanced perceptual priming hypothesis because this study was able to show that the anti-intrusion effect of lorazepam was directly related to its atypical inhibitory effect on implicit perceptual priming process: on Day 2, lorazepam rather than diazepam or the placebo impaired perceptual processing of traumatic information.

In one instance, the impairment of perceptual priming has also been observed in oxazepam ${ }^{19}$ when participants were tested at the time of theoretical peak plasma concentration of the drug. However, a recent study failed to show this newly proposed time-dependent effects of BZs on implicit memory processes by finding that lorazepam but not oxazepam significantly impaired perceptual priming at all time intervals including pre-peak, peak, post-peak drug concentration points. ${ }^{41}$

On the other hand, Ehlers and Clark ${ }^{5}$ suggested that if the individual lacks conceptual processing abilities, then the trauma memory will be relatively difficult to retrieve intentionally. Meanwhile, predominant use of conceptual processing during the event has been reported to reduce the extent of the intrusion. ${ }^{4}$ Naturally, poor conceptual processing will render the memory trace more vulnerable to triggering. Thus, we predicted that if a certain pharmacological treatment hampers conceptual priming, which is based on the semantic explicit memory system, then it may worsen involuntary intrusion of traumatic memories. Classically, only lorazepam, among all BZs, has been shown not to impair conceptual priming. ${ }^{17}$ However, recent results from pharmacological studies investigating the effect of BZs on conceptual priming have revealed some inconsistencies. In previous studies using a category generation task, Brown et al. ${ }^{11}$ found conceptual priming to be suppressed with lorazepam, while Bishop and Curran ${ }^{17}$ reported that conceptual priming is preserved under loraze- pam. And results on conceptual priming using a same-name exemplar test reported conceptual/lexical priming to be suppressed in participants administered with a single dose of lorazepam. ${ }^{42}$ The present experimental study did not find any differential effect of lorazepam compared to diazepam and placebo on conceptual priming at Day 2 of the experiment.

As predicted from the differential effect of lorazepam and diazepam on priming, only the IES-intrusion score of the diazepam group was slightly increased at Day 2 compared with Day 1 (baseline) in this study. These results suggest that diazepam may have an enhancement effect on intrusion. Support of the present disadvantageous effect of diazepam on intrusion of traumatic materials can also be found in previous BZs studies on automatic (i.e., unintentional) vs. controlled (i.e., intentional) retrieval processes. Vidailhet et al..$^{22}$ reported that lorazepam impaired automatic memory influences but diazepam left automatic use of memory intact. Although the majority of BZs studies demonstrated anterograde amnesia, it has been noted that BZs enhancing the automatic rather than controlling retrieval processes in response to cues can produce retrograde facilitation of memory. ${ }^{43}$ This enhancement effect of BZs including diazepam on the retrieval process does not only increase retrieval of target information, but at the same time, also increases intrusions of similar, competing material. ${ }^{44}$ Therefore, diazepam needs to be seriously reconsidered for the treatment of PTSD. A recent study suggested that the administration of lorazepam is more appropriate in all situations in which an amnesic effect is desired together with sedation, such as for surgery premedication or for patients in the intensive care unit, whereas the use of diazepam is more appropriate when only sedative effects are required. ${ }^{38}$

Taken together, we suggest a model for the anti-intrusion agents (Figure 3). The administration of lorazepam, which inhibits the retrieval process of the episodic memory and the perceptual priming but spares or enhances the semantic memory and conceptual priming, can reduce the extent of the intrusion. On the contrary, the administration of diazepam with the effect of saving or enhancing the episodic memory and perceptual priming tasks but impairing the semantic memory and conceptual priming may trigger the intrusion.

One of the strengths of this study was that all of the subjects were exposed to the same traumatic materials and had similar demographic backgrounds. Another is that we adopted a predrug design, where encoding of traumatic scenes occurred before drug administration, because we hypothesized that retrieval rather than acquisition and storage is affected by lorazepam. Almost all of the previous research on the cognitive effects of benzodiazepines in healthy subjects involves a postdrug design: encoding of the words and pictures occurred after drug administration. However, a pre-drug design rather 


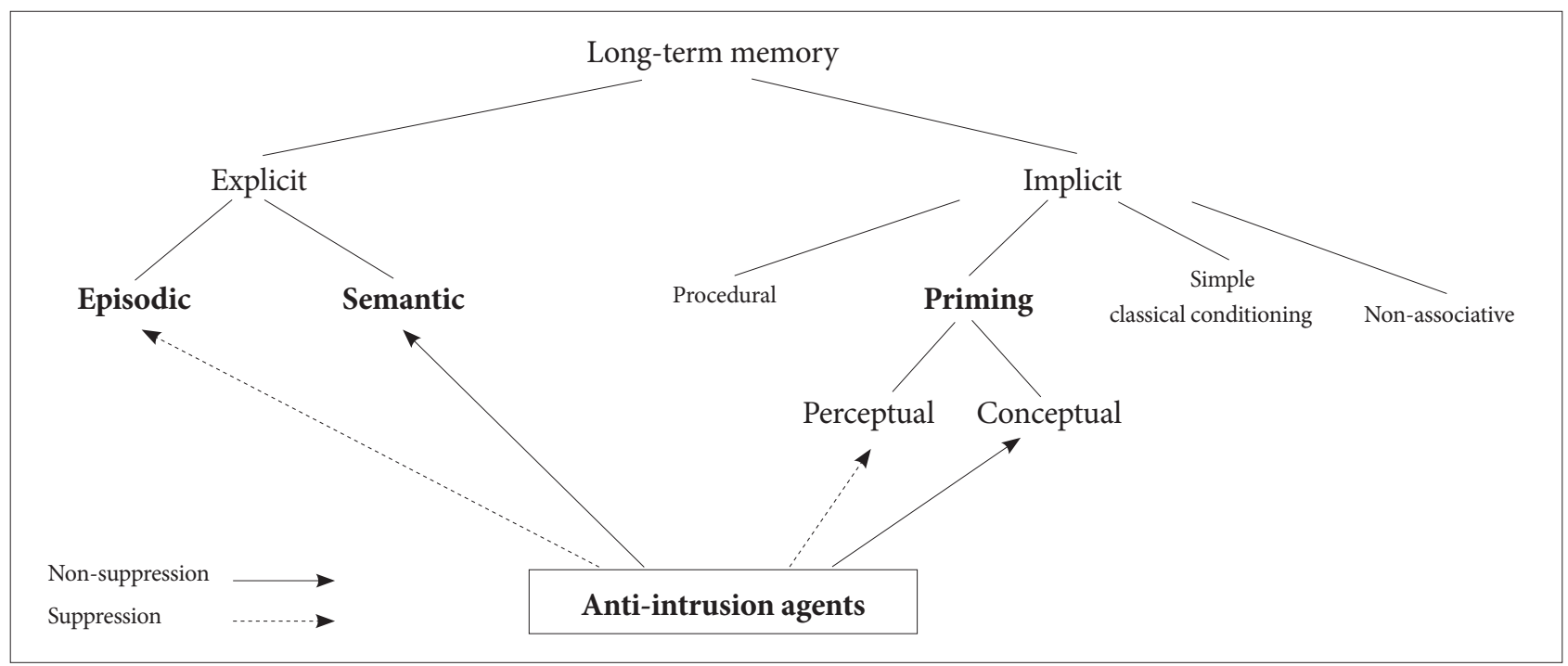

Figure 3. Hypothetical mechanism of anti-intrusion agents.

than post-drug design can be a better way to simulate the clinical trials for PTSD. The present results suggest that lorazepam can affect retrieval as well as acquisition.

Our study also has limitations. First, this study was a single dose trial. Thus, it is questionable whether the duration of the medication was enough to cause pharmacological effect. But laboratory studies have shown that a single dose of BZ is capable of causing significant effects on information retrieval. ${ }^{45,46}$

Second, a limitation in generalizing the present results to the clinical field exists because the negative experience was not real-life adversities, and the extent of trauma provocation was relatively mild. However, the validity of the present study is supported by the finding that cognitive processing influences memory in the same direction for real-life negative events, as well as memory for analogue trauma. ${ }^{34}$ Furthermore, Maes et al. ${ }^{47}$ suggested that PTSD is a dimensional rather than categorical disorder. This means that the assessment of mild reactions should yield results applicable to severe reactions. Actually, intrusions of posttraumatic stress responses have been shown to be phenomenologically similar to those of PTSD. ${ }^{48}$

In conclusion, this study indicates that the inhibitory effect on intrusion of lorazepam is appropriate, whereas the triggering effects on intrusion of diazepam need to be critically reconsidered in the treatment of PTSD. The pathways of anti-intrusive action of lorazepam remain uncertain and need further studies. However, Michael et al. ${ }^{49}$ showed that psychological manipulation also affects perceptual priming and re-experiencing symptoms after exposure to distressing video material. In their study the elaboration of the traumatic stories reduced the enhanced perceptual priming effect and the relative probability of reexperiencing symptoms. Their results indicate that the anti-intrusive effect of lorazepam in this study seems to be related to its atypical and unique inhibitory effect on the im- plicit perceptual priming process and its effect on sparing the conceptual priming process which is related with the intentional retrieval of the trauma memory.

\section{Acknowledgments}

This work was supported by the Korea Science and Engineering Foundation (KOSEF) grant funded by the Korean government (MEST) (R012006-000-10803-0) and by the Hallym University Medical Center grant funded by the Kangnam Sacred Heart Hospital. We acknowledge the contributions of all the study team members of Posttraumatic Growth Center, especially SH Song (Soon Chun Hyang University Hospital), SJ Kwon, SH Lim, EJ Lee (Chungnam National University), and CS Jung (The Catholic University). This work was conducted at the Department of Psychiatry of Daejeon St. Mary's Hospital, The Catholic University.

\section{REFERENCES}

1. Krans J, Näring G, Becker ES, Holmes EA. Intrusive trauma memory: a review and functional analysis. Appl Cognit Psychol 2009;23:1076-1088.

2. Amir N, McNally RJ, Wiegartz PS. Implicit memory bias for threat in posttraumatic stress disorder. Cognit Ther Res 1996;20:625-635.

3. Brewin CR, Dalgleish T, Joseph S. A dual representation theory of posttraumatic stress disorder. Psychol Rev 1996;103:670-686.

4. Conway MA, Pleydell-Pearce CW. The construction of autobiographical memories in the self-memory system. Psychol Rev 2000;107:261-288.

5. Ehlers A, Clark DM. A cognitive model of posttraumatic stress disorder. Behav Res Ther 2000;38:319-345.

6. Roediger HL 3rd. Implicit memory. Retention without remembering. Am Psychol 1990;45:1043-1056.

7. Ghoneim MM, Mewaldt SP. Benzodiazepines and human memory: a review. Anesthesiology 1990;72:926-938.

8. Curran HV. Benzodiazepines, memory and mood: a review. Psychopharmacology (Berl) 1991;105:1-8.

9. Fluck E, File SE, Springett J, Kopelman MD, Rees J, Orgill J. Does the sedation resulting from sleep deprivation and lorazepam cause similar cognitive deficits? Pharmacol Biochem Behav 1998;59:909-915.

10. Giersch A, Boucart M, Elliott M, Vidailhet P. Atypical behavioural effects of lorazepam: clues to the design of novel therapies? Pharmacol Ther 2010;126:94-108.

11. Brown MW, Brown J, Bowes JB. Absence of priming coupled with substantially preserved recognition in lorazepam-induced amnesia. Q J Exp Psychol A 1989;41:599-617. 
12. Curran HV, Gorenstein C. Differential effects of lorazepam and oxazepam on priming. Int Clin Psychopharmacol 1993;8:37-42.

13. Danion JM, Peretti S, Grangé D, Bilik M, Imbs JL, Singer L. Effects of chlorpromazine and lorazepam on explicit memory, repetition priming and cognitive skill learning in healthy volunteers. Psychopharmacology (Berl) 1992;108:345-351.

14. Knopman D. Unaware learning versus preserved learning in pharmacologic amnesia: similarities and differences. J Exp Psychol Learn Mem Cogn 1991;17:1017-1029.

15. Legrand F, Vidailhet P, Danion JM, Giersch A, Grangé D, Linden M, et al. Time course of the effects of diazepam and lorazepam on perceptual priming and explicit memory. Psychopharmacology (Berl) 1995; 118:475-479.

16. Sellal F, Danion JM, Kauffmann-Muller F, Grangé D, Imbs JL, Van der Linden $\mathrm{M}$, et al. Differential effects of diazepam and lorazepam on repetition priming in healthy volunteers. Psychopharmacology (Berl) 1992;108:371-379.

17. Bishop KI, Curran HV. An investigation of the effects of benzodiazepine receptor ligands and of scopolamine on conceptual priming. Psychopharmacology (Berl) 1998;140:345-353.

18. Bishop KI, Curran HV. Psychopharmacological analysis of implicit and explicit memory: a study with lorazepam and the benzodiazepine antagonist flumazenil. Psychopharmacology (Berl) 1995;121:267-278.

19. Buffett-Jerrott SE, Stewart SH. Cognitive and sedative effects of benzodiazepine use. Curr Pharm Des 2002;8:45-58.

20. File SE. Effects of lorazepam on psychomotor performance: a comparison of independent-groups and repeated-measures designs. Pharmacol Biochem Behav 1992;42:761-764.

21. Stewart SH, Rioux GF, Connolly JF, Dunphy SC, Teehan MD. Effects of oxazepam and lorazepam on implicit and explicit memory: evidence for possible influences of time course. Psychopharmacology (Berl) 1996; 128:139-149.

22. Vidailhet P, Kazes M, Danion JM, Kauffmann-Muller F, Grange D. Effects of lorazepam and diazepam on conscious and automatic memory processes. Psychopharmacology (Berl) 1996;127:63-72.

23. Danion JM, Zimmermann MA, Willard-Schroeder D, Grange D, Singer L. Diazepam induces a dissociation between explicit and implicit memory. Psychopharmacology (Berl) 1989;99:238-243.

24. Fang JC, Hinrichs JV, Ghoneim MM. Diazepam and memory: evidence for spared memory function. Pharmacol Biochem Behav 1987;28:347352.

25. Schlagman S, Kvavilashvili L. Involuntary autobiographical memories in and outside the laboratory: how different are they from voluntary autobiographical memories? Mem Cognit 2008;36:920-932.

26. Structured clinical interview for DSM-IV (SCID-I) - Research version. New York, NY: Biometrics Research; 2007.

27. Beck AT. Depression: clinical, experimental, and theoretical aspects. Philadelphia: University of Pennsylvania Press; 1967.

28. Speilberger CD, Gorsuch R, Lushene R, Vagg P, Jacobs G. Manual for the State-Trait Anxiety Inventory. Palo Alto, CA: Consulting Psychologists; 1983.

29. Horowitz M, Wilner N, Alvarez W. Impact of Event Scale: a measure of subjective stress. Psychosom Med 1979;41:209-218.
30. Yi SM, Eun HJ. A study of reliability and validity on the Korean version of impact of event scale. J Korean Neuropsychiatr Assoc 1999;38:501513.

31. Foa E. The Posttraumatic Diagnostic Scale (PDS) Manual. Minneapolis, MN: National Computer Systems; 1995.

32. Halligan SL, Michael T, Clark DM, Ehlers A. Posttraumatic stress disorder following assault: the role of cognitive processing, trauma memory, and appraisals. J Consult Clin Psychol 2003;71:419-431.

33. Murray J, Ehlers A, Mayou RA. Dissociation and post-traumatic stress disorder: two prospective studies of road traffic accident survivors. $\mathrm{Br}$ J Psychiatry 2002;180:363-368.

34. Halligan SL, Clark DM, Ehlers A. Cognitive processing, memory, and the development of PTSD symptoms: two experimental analogue studies. J Behav Ther Exp Psychiatry 2002;33:73-89.

35. Ehlers A. Data-Driven Versus Conceptual Processing Questionnaire. Unpublished manuscript; 1998.

36. Lee YH, Song JY. A Study of the reliability and the validity of BDI, SDS, MMPI-D scale. Korean J Clin Psychol 1991;10:98-113.

37. Kim JT, Shin DK. A study based on the standardization of the STAI for Korea. New Med J 1978;21:1223-1229.

38. Di Lazzaro V, Pilato F, Dileone M, Tonali PA, Ziemann U. Dissociated effects of diazepam and lorazepam on short-latency afferent inhibition. J Physiol 2005;569:315-323.

39. Michael T, Ehlers A, Halligan SL. Enhanced priming for trauma-related material in posttraumatic stress disorder. Emotion 2005;5:103-112.

40. Ehlers A, Michael T, Chen YP, Payne E, Shan S. Enhanced perceptual priming for neutral stimuli in a traumatic context: a pathway to intrusive memories? Memory 2006;14:316-328.

41. Martin J, Matthews A, Martin F, Kirkby KC, Alexander J, Daniels B. Effects of lorazepam and oxazepam on perceptual and procedural memory functions. Psychopharmacology (Berl) 2002;164:262-267.

42. Boucart M, Biederman I, Cuervo C, Danion JM, Wagemans J. Effect of benzodiazepines on structural and conceptual/lexical priming. Psychopharmacology (Berl) 2002;165:43-50.

43. Curran HV. The psychopharmacology of memory. In: Tulving E, Craik F, editors. The Oxford handbook of memory. New York: Oxford University Press, 2000, p. 539-556.

44. Fillmore MT, Kelly TH, Rush CR, Hays L. Retrograde facilitation of memory by triazolam: effects on automatic processes. Psychopharmacology (Berl) 2001;158:314-321.

45. Kožena L, Frantik E, Horvath M. Vigilance impairment after a single dose of benzodiazepines. Psychopharmacology (Berl) 1995;119:39-45.

46. Drummer OH. Benzodiazepines- effects on human performance and Behavior. Forensic Sci Rev 2002;14:1-14.

47. Maes M, Delmeire L, Schotte C, Janca A, Creten T, Mylle J, et al. The two-factorial symptom structure of post-traumatic stress disorder: depression-avoidance and arousal-anxiety. Psychiatry Res 1998;81:195-210.

48. Ehlers A, Steil R. Maintenance of intrusive memories in posttraumatic stress disorder: a cognitive approach. Behav Cogn Psychother 1995;23: 217-249.

49. Michael T, Ehlers A. Enhanced perceptual priming for neutral stimuli occuring in a traumatic context: two experimental investigations. Behav Res Ther 2007;45:341-358. 